\title{
Chronicling Country-Specific Response to Covid-19 Pandemic in Africa: From the Perspective of Ghana
}

\author{
Daniel Odoom $^{1} \quad$ Joseph Obeng-Baah $^{1} \quad$ Lawrencia Agyepong $^{1} \quad$ Gloria Dwamena Boaten ${ }^{2}$ \\ Hilda Edem Senanu ${ }^{3} \quad$ Gifty Kabukie Zikpi ${ }^{3} \quad$ Ebenezer Asumang $^{4}$ Selorm Kakraba Owusu ${ }^{5}$ \\ Julius Caesar Anadem ${ }^{6}$ \\ 1.Department of Communication Studies, Ghana Institute of Journalism, Ghana \\ 2.Presbyterian Church of Ghana, Head Office, Ghana \\ 3.School of Graduate Studies and Research, Ghana Institute of Journalism, Ghana \\ 4.PRION Global Development GmbH, Ghana \\ 5.Ghana Education Service, Accra, Ghana \\ 6.Abusua and Ultimate FM, EIB Network, Ghana
}

\begin{abstract}
Health is closely tied to human development and the overall development of a nation. Indeed, throughout history, improved public health has been a major determinant of development. Within this context, the consequences of infectious diseases including the novel Coronavirus are not in doubt. Particularly, the COVID-19 pandemic has destabilized the much-talked about world civilization with many nations still under various infection control measures. Globally, the pandemic has resulted in several losses in the areas of jobs, income, government revenues, foreign direct investments, among others. Beyond the incalculable economic losses, the pandemic constitutes a great threat to physical, social and mental health. Since the outbreak of the pandemic, several studies have been conducted on the experiences of different countries to help deepen global knowledge on the pandemic. This review paper chronicles the Ghanaian experience of COVID-19 and attempts to probe whether the country's overall response to the disease is worthy of emulation by other nations. Part one introduces the paper by looking at the intersection of health and development, a brief history of COVID-19, challenges associated with the pandemic and measures some countries have employed to rebuild their economies. Part two describes the key issues underpinning the spread of the virus in Ghana whilst part three considers the efforts key stakeholders employed to contain and manage the spread of the virus. Part four focuses on the challenges Ghana has faced in the management of the pandemic whereas the concluding part presents the core issues which should engage the attention of stakeholders.
\end{abstract}

Keywords: COVID-19 pandemic, misinformation, social risk amplification and attenuation theory, health services, development

DOI: $10.7176 / \mathrm{NMMC} / 97-03$

Publication date:August $31^{\text {st }} 2021$

\section{Introduction}

Disbursements on health constitute an investment in human capital formation, which ultimately contributes to the overall development of nations. The health of a nation's population is significantly tied to its development. No economic, social, and political challenges confronting the world can better be addressed without a careful understanding of the role of good healthcare services. In effect, ensuring better health services is regarded as a strategic development objective of all nations (Ruger, 2003). In spite of this recognition, vulnerable and socially disadvantaged people throughout the world continue to have less access to health services, get sicker and die earlier than the life expectancy of people in more privileged social positions (Kim, 2020). Unfortunately, this inequity manifests across the globe despite the fact that, globally, the world is experiencing an era of unprecedented wealth, knowledge, and health awareness.

Health is equally linked to the standard of living of a country. Lack of access to improved healthcare services is intricately linked to poverty throughout the world. In other words, efforts at reducing poverty globally are directly threatened by the poor health conditions of the population. Health is, therefore, central to the global agenda of reducing poverty and to meeting the Sustainable Development Goals. Weak and inequitable health systems especially those that are fraught with severe human resource acuity, inadequate infrastructure or poor financing frameworks serve as a key obstacle to scaling up the disease prevention and control programs that are required to achieve the health objectives of nations (Lim and Lee, 2020). Besides, measures to reduce child and maternal mortality and the burden of HIV/AIDS, tuberculosis, and malaria and most recently the COVID-19 pandemic continue to be threatened by poor health systems (Lim and Lee, 2020).

The novel coronavirus outbreak was first documented in the Chinese city of Wuhan in Hubei Province in December, 2019. As several people in the initial cases of infection had visited a large seafood and live animal market, some investigators were prompted to have an unconfirmed suspicion that this might be the initial source of infection. The Chinese Center for Disease Control and Prevention, along with other related institutions, 
quickly identified the pathogen as a new type of coronavirus. The World Health Organization (WHO) subsequently issued alerts on 30th December, 2019 and on 30th January 2020 and declaring this viral infection as a Public Health Emergency of global concern. On the 11th of February, 2020, the International Committee of Taxonomy of Viruses identified the virus to be a Severe Acute Respiratory Syndrome (SARSCoV-2) based on its phylogenetic relationship with the coronavirus that caused the SARS outbreak in 2003. Around the same period, WHO announced COVID-19 as the name of the disease caused by the novel coronavirus. The description was based on the WHO guidelines for Animal Health and the Food and Agricultural Organization (FAO). From the initial announcement of a few cases of coronavirus-related pneumonia, COVID-19 has since evolved into a global pandemic of historical magnitude (Wang, Wang, and Wang, 2021).

As of March 2021, 100 million people in over 200 countries have been confirmed to have been infected with the virus and two million people have died of COVID-19 (Wang et al, 2021). Since then, the virus continues to destabilize the entire world, exposing the vulnerability of health systems around the world and the unpreparedness of many countries to confront pandemics of this magnitude. According to Ozili and Arun, as cited in Antwi-Boasiako et al. (2021), the COVID-19 has had a spill-over effect on almost every facet of life. Notable areas where the disease appears to exert the devastation include hospitality industry, health systems, travel, finance, and sports. The pandemic, in very significant ways, has and indeed continues to challenge the resilience of nations, companies, communities, families, and individuals (Ozili and Arun, cited in AntwiBoasiako et al., 2021).

The COVID-19 pandemic presents the biggest economic crisis the world has experienced in recent history, according to the World Bank in its report, Global economy prospect, published in June 2020. (The World Bank, 2020). The report discusses the short- and long-term impacts of the pandemic and the damage it has dealt to the economic fortunes of nations around the world. The basic estimates indicate a fall in global Gross Domestic Product (GDP) by $5.2 \%$ in 2020 . There has been a reflection on the trade-off between efficiency and resilience of the global value chain $(\mathrm{GVC})$. The pandemic is expected to plummet most countries into recession with per capita income experiencing huge contractions amongst countries on a scale never before experienced since 1870 (The World Bank, 2020; Zhou, 2021). The pandemic has also increased global debt levels bringing into question the issue of equitable sharing of cost in relation to debt repayment which has become a hot-button issue in the current debates on the global global economy. It is estimated that East Asia and Pacific would grow by only $0.5 \%$ whilst South Asia would experience a $2.7 \%$ shrink. Also, Sub-Saharan Africa is expected to have 2.8\% economic fall, Middle East and North Africa having 4.2\%, Europe and Central Asia experiencing 4.7\% fall, and Latin America seeing 7.2\% fall. Clearly, there is a recession in the global economy, with countries where there are serious infection cases becoming the most badly hit (McKibbin and Fernando, 2020; Zhou, 2021).

The virus has had a toll on health systems globally. The world was in no way prepared for this pandemic and, as such, the virus has exerted unanticipated pressures on hospitals and health facilities across the world. The inadequacy and unpreparedness of health facilities to receive and treat infected persons has become overwhelmingly evident. Indeed, poor health systems across the globe constituted a major cause of the rise in deaths in the early stages of the virus. The sudden upwelling of the virus caused a stretch in medical resources around the world as there was a shortage of health workers and Personal Protective Equipment (PPE). Healthcare personnel all over the world continue to face a multitude of challenges including long working hours, stress and fatigue, emotional distress, and psychological imbalance, as well as increasing vulnerability to infection for themselves and their families. The situation is even worse in developing countries that have poor health systems.

Africa reported its first case of coronavirus on February 14, 2020 in Egypt. The pandemic has since spread to all parts of the continent with several millions of confirmed cases being reported As of June 24, 2021, the number of confirmed cases in African continent stood at 5, 363, 727 including 95,259 confirmed cases in Ghana (Galal, 2021). These figures represent an estimated 2.97 percent of the COVID-19 global infections which stood at 180 million and 3,894,889 deaths, according to the Pan American Health Organization, the regional bureau of the World Health Organization for the Americas. On the African continent, South Africa appears to be the country worst hit by the pandemic, with over 1.59 million confirmed cases of infections as of May 11, 2021 (Galal, 2021). Unlike Europe, Asia and America, Africa has not been significantly hit by the pandemic relative to other parts of the world. Nevertheless, the poor health systems across the continent and the fragility of the African economy suggest that African governments need to put in place strategic measures to deal with the pandemic before cases of infection and deaths overwhelm them.

Many countries including Japan, the United States, Australia, and Britain are approving large stimulus packages for various sectors of their economies to mitigate the adverse effect of the pandemic (Duffin, cited in Antwi-Boasiako et al., 2021). Japan, in the estimation of Duffin, as cited in Antwi-Boasiako (2021), is the nation which has passed the biggest stimulus package amounting to about 117trillion Yen (almost USD\$1.1 trillion). Similar measures have also been made in Africa to help contain the negative effects of the pandemic. 
Countries including South Africa, Nigeria, Ghana, and Namibia have all instituted various plans including stimulus packages to deal with the impact of the pandemic. For example, South Africa launched a R500 billion (about US\$26.3 billion) stimulus package in April 2020. At the initial stages of the pandemic, the Ghana government allocated a cedi equivalent of $\$ 100$ million to improve infrastructure capacity of the health sector for the country to be able to efficiently manage COVID-19 cases and other health emergencies, acquire the necessary equipment and logistics, and to be able to actively engage the population through education and other sensitization and awareness creation measures. Clearly, various measures have been adopted by governments across the globe to respond to the COVID-19 pandemic. In support of this claim, Hale et al. (2020) submit that, globally, the increasing spread of the COVID-19 has triggered varying responses and efforts from governments and have called for the need for researchers to critically examine the responses that various stakeholders including governments across the globe have made to manage the pandemic. In line with this call, this paper focuses on the measures and strategies that Ghana adopted to manage the pandemic and the challenges associated with the emergency pandemic response.

\section{The spread of the virus in Ghana: Key issues and factors}

Ghana announced its first COVID-19 cases on March 12, 2020. This was reported by the health minister, Kweku Agyeman-Manu, in an emergency press conference and a press release which disclosed that two persons had been infected by the virus. The two were imported cases from Norway and Turkey (Agyeman-Manu, 2020; Ghana Health Service [GHS], 2020). Efforts that have been invested from the onset of the detection of the virus in Ghana by, the Government of Ghana demonstrate a serious commitment and a determination to confront the pandemic head on in order to protect lives. The Ministry of Health quickly put into force a contact tracing mechanism to identify and test those who had been in contact with the two infected persons. By March 17, 2020, a total of 143 suspected cases had been tested by the Noguchi Memorial Institute for Medical Research (NMIMR) and the Kumasi Centre for Collaborative Research (KCCR) out of which seven persons tested positive (Ghana Health Service, 2020; Ministry of Health, 2020). This led to the intensification of public information and education using both traditional and new media by various stakeholders including the Ministry of Information and the Ministry of Health. The Ghana Health Service regularly updated information on its website and the president has, since the arrival of the pandemic on Ghana's shores, issued multiple executive directives in the interest of public safety (President of Ghana, 2020a).

The Ministry of Information was also tasked to lead a nationwide public campaign on COVID-19 preventive measures (Ministry of Health, 2020). Subsequently, the ministry engaged the media and other key stakeholders on various issues relating to COVID-19. President Nana Addo Dankwa Akufo-Addo also gave regular updates through a state of the nation address on matters concerning COVID-19 coupled with regular press briefings organized by the Ministry of Information in conjunction with the Ministry of Health (President of Ghana, 2020a\&b). This provided an opportunity to the public to receive regular policy updates and other related efforts by the government and its collaborators in the fight against the pandemic. Reporters who attend these press briefings are given opportunities to ask questions related to the COVID-19 situation in the country. These media events also provided an expert platform for health professionals to share critical COVID-19 information on prevention with Ghanaians.

The president, on March 15, 2020, announced an initial ban of four weeks on all public gatherings including conferences, workshops, funerals, festivals, political rallies, sporting events and religious activities, such as services in churches and mosques (President of Ghana, 2020b). Funerals were limited to private burials with numbers not exceeding attendance capacity of twenty-five persons. These drastic social measures were followed immediately by school closures across country. Similarly, in line with practices elsewhere, the government put a travel ban on all travelers coming from countries with more than 200 confirmed cased of COVID-19. There was also a mandatory 14-day quarantine of all travelers arriving in the country $48 \mathrm{hrs}$ prior to the closure of the country's borders. Ghana's borders were closed temporarily and, then, extended as the government deemed necessary. Indeed, restriction on travel and the closure of borders effective March 22, 2020 continued until it was reviewed on September 1, 2020 (KPMG, 2020). The president announced further that land and sea borders would continue to remain closed until further notice.

In efforts to contain the threatening wave of infections in the major densely populated areas in the country's major cities, President Akufo-Addo announced a partial lockdown in the Greater Accra and Greater Kumasi metropolises at the end of March, 2020 under the Imposition of Restrictions Act, 2020 (Act 1012). In the Greater Accra Metropolis, the directive affected the Accra Metropolis, Tema Metropolis; Tema West Municipality; Ledzokuku Municipality; Krowor Municipality; Adentan Municipality; Ashiaman Municipality; LaNkwantanang-Madina Municipality; La-Dade-Kotopon Municipality; Okaikwei North Municipality; Ablekuma North Municipality; and Ablekuma West Municipality. Other areas including Ablekuma Central Municipality; Ayawaso East Municipality; Ayawaso North Municipality; Ayawaso West Municipality; Ayawaso Central Municipality Ga West Municipality; Ga North Municipality; Ga Central Municipality; Ga South Municipality; 
Ga East Municipality; Korle-Klottey Municipality; Weija/Gabae Municipality; Kpone Katamanso Municipality; and Awutu Senya East Municipality were also affected in the Greater Accra Metropolis. In the Greater Kumasi Metropolitan area and adjoining districts, areas such as the Kumasi Metropolis; Asokwa Municipality; Suame Municipality; Old Tafo Municipality; Oforikrom Municipality; Asokore Mampong Municipality; and Kwadaso Municipality were affected. Other areas affected areas included Atwima Nwabiagya Municipality; Kwabre East Municipality; Ejisu Municipality; Afigya-Kwabre South District; Bosomtwi District; Atwima Kwanwoma District; and Atwima Nwabiagya North District.

Key among the issues associated with the lockdown was the decision by the government to ground intercity movement of both commercial and private vehicles as well as aircrafts in the lockdown areas of the country with the exception of vehicles and aircrafts providing essential services. This was done to ensure the strict implementation of the lockdown in order to achieve real results in COVID-19 prevention and containment. Riders of motorbikes were not allowed to transport additional persons and all intra-city passenger vehicles such as vans (trotros) and taxis were required to reduce the number of passengers to observe appropriate social distancing and hygiene protocols (President of Ghana, 2020b). The only people exempted from this restriction were members of the executive, legislature, and the judicial branches of government. Others that the president identified in his state of the nation addresses as providing essential services were people in the food supply chain, and workers in the beverage, pharmaceutical, paper, and plastic packaging industries. Workers engaged in environmental and sanitation activities, energy, railway construction and mining, telecommunication and law enforcement were also exempted.

Enhanced surveillance in the form of active search for cases and contact tracing strategies were activated to ensure early detection, isolation, and treatment of all confirmed cases. The Ghana Health Service with the support of Ghana Field Epidemiology and Laboratory Training Program (FELTP) mapped out all existing cases, conducted a risk assessment, and sampled members of households within 1-2km radius of cluster of cases based on the setting. In essence, the enhanced surveillance and contact tracing strategy helped the country to identify a significant number of cases, of whom about $93 \%$ were asymptomatic. The restrictions in Greater Accra and Greater Kumasi were lifted on April 20, 2020, and the use of face masks in public spaces became mandatory on April 26, 2020. At the core of these measures were activities on awareness creation on the disease and its transmission as well as preventive measures including the washing of hands with soap under running water, using alcohol-based hand sanitizers and the wearing of face masks (Serwornoo and Abrokwah, 2020). These were critical measures that had the potential to significantly curb the uncontrollable spread of the virus in Ghana.

In spite of all the stringent measures adopted by the government to contain the pandemic, Ghana witnessed an increase in the number of confirmed cases. Just after a year over when the country announced the first two confirmed cases, Ghana COVID 19 cases stood at 91,477 with 89,301 recoveries and 763 deaths. By July 19, 2021, Ghana had 2,735 active cases with a weekly surge of 1,430 from the previous week (WHO, 2021). Although the figures might not present a severe picture of COVID-19 situation in the country, the prevalence of non-compliance with the safety protocols such as social distancing and wearing of mask suggests that Ghana's situation can deteriorate very quickly. Indeed, it is clear that if enforcement mechanisms are not reinforced to ensure full compliance with the safety protocols and other preventive measures the pandemic situation may get of hand in the country. Several factors have accounted for the rise in COVID-19 cases in Ghana as we discuss below.

First and foremost, the rise of globalization is seen as a stimulus for social and economic development. On the downside, however, globalization has facilitated the spread of global threats such as the COVID-19 pandemic. Advancements in transportation technology have made human interaction easier than ever before and so has human interaction with invisible viruses and pathogens such as the novel coronavirus. In that context, the globalization phenomenon comes with costs and consequences far beyond the visible economic benefits (Nsibambi, 2001). The easy movement of people, goods, and services that is a common feature of globalization is the very factor that facilitated the easy travel of the virus into Ghanaian borders. This is evidenced by the fact that the few cases which were earlier recorded were from two foreign individuals who had returned to Ghana from Norway and Turkey (Ghana News Agency, 2020). These early cases have had a ricocheting effect on the entire country resulting in tens of thousands of domestic infections. Critics of the government's handling of the pandemic are convinced that the failure to close the country's border to both land and air travel is largely accountable for the country falling victim to it.

Misinformation and misconceptions about the disease have also played a major role in the spread of the virus in Ghana (Tabong and Martin, 2021). According to the theory of social risk amplification and attenuation, sources of information and channels of transmission are essential in effective communication given that information is communicated via social amplification stations (Kasperson and Kasperson, 1996). Communication networks such as telephones, media and direct conservations are often employed to produce and transmit information through social amplifications. Consequently, individuals become the victims of messages produced and communicated through various networks of amplification (Kasperson and Kasperson, 1996). 
Misinformation about COVID-19 occurs in many forms ranging from conspiracy theorists to religious fundamentalists (Barua et al., 2020). Some of the misconceptions about COVID-19 in Ghana is the peddling of the myth that the country's tropical climate is too hot for the virus to survive in it. The religious fundamentalist myth revolves around a faith declaration that asserts the healing and protective power of prayers to ward off the disease. Others simply believe in the genetic superiority of the physiology of the average Ghanaian that ensures immunity from health threats such as COVID-19. There are also inordinate volumes of false information and myths about the disease that are widely trafficked and shared on social media that negatively influence people's perception about the disease. In effect, these misconceptions have been fuelled by religious beliefs, inadequate information, and misinformation about the virus. All these misconceptions and misinformation have led to a situation where a section of Ghanaians simply disregard the safety measures instituted to curb the spread of the virus (Quakyi et al., 2021).

Additionally, cultural inhibitors such as language barriers have also contributed to the spread of the virus. Information on the disease has not easily been made available and accessible to all Ghanaians. Even where information on the virus was available, the format and language used to communicate this information did not seem to help people to comprehend the messages being communicated. Most of the information and daily updates on COVID-19 are circulated in English and Akan. There are many people who would struggle to understand pieces of information circulated in the media using languages other than their native language. For most of the Akan-speaking people, it was relatively easier for them to follow some of the conversations in the media around the pandemic. However, for many Ghanaians who neither understand Akan nor English, it is extremely difficult for them to grasp the issues as discussed in the media and other platforms. Moreover, illiteracy is responsible for the spread of the infection in the country. Much of the communication efforts made to create awareness about the virus have been conducted in the English language. Most of the discussions in the media and on other communication platforms were mostly in English. A detailed examination of these communication acts indicated that one would require a high level of proficiency in English to meaningfully understand the discussion. The conventional assumption has been that major cities in Ghana - Accra and Kumasi - for instance, have high levels of English literacy rates. However, there are still large communities within Accra and Kumasi with very low literacy rates and, therefore, incapable of understanding pertinent and life-saving messages on COVID-19 that are communicated in English.

Sheer popular social indiscipline can adversely impact the ability of countries to deal with crisis such as a global health pandemic (Brown, 2020). While some individuals, churches and institutions adhered to the safety protocols, it has been widely reported in the media that many people in communities around the country have not taken these protocols seriously. Leaders of some churches, for example, were arrested for disregarding the safety protocols. Also, in places where lockdown occurred some persons were arrested by state security forces for violating lockdown orders to stay at home. In many communities mass gatherings in small pubs, weddings, funerals, political rallies, markets, and congestion in public transports that had been banned through presidential directives were still taking place. These acts of outright disregard for the safety protocols have, in significant ways, contributed to the spread of the disease in Ghana. As of April 14, 2020, the Ghana Police Service had arrested over 400 people for violating the lockdown directives including the ban on social gatherings (Brown, 2020). A number of persons in areas such as Accra, Kumasi and Takoradi were arrested for their refusal to comply with the infection control measures. In Akwapim Akropong in the Eastern Region, people were also arrested for flouting COVID-19 protocols during the installation of the traditional chief of the Akwapim Paramountcy.

Finally, political activities have been complicit in the spread of COVID-19 in Ghana (Quakyi, 2020). The outbreak of the COVID-19 pandemic coincided with the primaries and general elections season in Ghana. As such, members of political parties actively campaigned and canvassed for votes in homes and on the streets of cities and towns throughout the country and, in most instances, ignored COVID-19 safety protocols. Other campaign-related activities in which safety protocols were ignored included so-called health walks involving huge gatherings. The governing New Patriotic Party and the largest opposition party, the National Democratic Congress, mostly disregarded the safety protocols during this early crucial period of the pandemic. The situation took a nosedive especially around the final days ahead of the general elections when most political parties embarked on marathon political campaigns across the country to canvass for votes. These events also contributed to the spread of the virus as little or no effort was made to ensure proper observance of the COVID-19 protocols such as social distancing and wearing of nose masks. It did not, therefore, come as a shock when it was reported in the media that some politicians including ministers and parliamentarians had tested positive for coronavirus.

Efforts by various stakeholders to contain and manage the spread of Covid-19 in Ghana

Several efforts were put in place by various stakeholders in Ghana to help contain the spread of the disease. This section focuses on the efforts adopted by key stakeholders in the country to help deal with the pandemic.

As part of dealing with the pandemic, the Government of Ghana set up an Inter-Ministerial Committee on 
COVID-19. The Committee was made up of various representatives from the various ministries whose responsibilities have relevance to issues relating to public health. The main objectives of the Inter-Ministerial Committee were to limit and stop the importation of the virus, contain its spread, and provide adequate care for the sick. This was subsequently expected to limit the impact of the virus on social and economic life and inspire the expansion of domestic capability and deepen resilience. The committee upon its inauguration put in place some immediate measures to contain the spread of the virus and the associated COVID-19 disease. The measures included a travel advisory which strongly discouraged all travels to Ghana except for citizens and persons with residence permits. A mandatory 14-day self-quarantine and testing period for travellers entering Ghana was imposed. Generally, these measures proved to be instrumental identifying 105 out of the 1,030 persons entering the country around the period as carriers of the virus. The Committee also ensured the closure of all land, sea and air boarders to human traffic coupled with the suspension of all public gatherings, closure of all schools and selected businesses and the strict observance of enhanced hygiene procedures and social distancing.

The dissemination of relevant information and facts during the period of the pandemic is essential. It is with these pieces of information and facts that individuals can understand the situation and take appropriate steps to prevent the spread of the disease. On its part, the Ministry of Information instituted measures to deal with the pandemic as the state institution charged with the responsibility to ensure the day-to-day dissemination of relevant information on COVID-19 to the public. It is also responsible for communicating the various interventions made by the government to control the spread of the disease. To this effect, the Ministry organises regular press briefings to communicate the seriousness of the pandemic, the rate of infections in the country and the need to adhere to the laid down safety protocols. They also provide the platform to other stakeholders including public health professionals to bring citizens up to speed on the steps being taken to fight the pandemic (Ghana News Agency, 2020). These regular updates have contributed to creating awareness about the spread of the disease thereby empowering ordinary Ghanaians to take the appropriate steps to protect themselves and others.

The Ministry of Health is at the forefront of the battle, influencing and implementing government decision making on the pandemic. The Ministry, through the Ghana Health Service, ensured that healthcare workers and facilities including COVID-19 isolation centres are available and active upon demand. The Ministry has taken the necessary steps to ensure that these facilities and frontline workers are well equipped to provide the necessary healthcare services for infected persons. Although, the infection rate is high, coupled with several deaths, these facilities and personnel have provided the needed treatment and case management that have resulted in significant numbers of recovery. The Ministry of Health also provides updates on the number of infections recorded daily and interventions to contain the spread of the virus. Furthermore, they carry out contact-tracing, testing, and counselling for infected persons as well as those who have recovered (Ministry of Health, 2020). This cumulative effort has resulted in the development of a credible database which is essential to the fight against the pandemic. Besides, an amount of $\mathrm{GH} \varnothing 323$ million was disbursed as a relief package for frontline health workers. This went into the procurement of personal protective equipment (PPE), tax waivers, allowances, transportation and COVID insurance. The tax incentive was designed as a token compensation to encourage healthcare workers, especially frontline health personnel, to continue to make sacrifices in caring for those infected with the coronavirus disease, and in caring for the sick in general. As part of incentive, each health personnel and allied professionals at the forefront of the fight against coronavirus was insured to the sum of GH $\notin 350,000$. Additionally, all frontline health workers were paid an additional allowance of 50 percent of their basic salary (Xinhuanet, 2021). The Ministry also worked to ensure the approval of a daily allowance of GHф150 to be paid to each of the contact tracers in the country. This approach largely helped in containing and managing the spread of the virus as many people who had had contacts with infected persons were traced, isolated, and treated.

In addition to the central role of the core ministries, the Ministry of Defence as an important stakeholder helped in the management of the COVID-19 in the country especially in the area of lockdown compliance. The military possesses a command network and a pool of disciplined manpower that can be deployed at relatively short notice to supplement civilian frontline services during national emergencies. The Ghana Armed Forces (GAF), under the umbrella of the Ministry of Defence, availed its resources and services to assist civil society and the government to tackle this national emergency. Initially, personnel of the Ghana Armed Forces (GAF) and other security services were deployed to enforce full public compliance to a partial lockdown that was imposed in Accra and Kumasi. Also, as a result of physical threats and attacks on healthcare personnel conducting contact tracing, the GAF was assigned the additional task of providing security for these personnel. Another major contribution of the Ministry of Defence was the opening up of the 37 Military Hospital as holding and treatment centres for COVID-19 infected persons. The GAF also contributed to the establishment of the Ghana Infectious Disease Centre by providing the expertise and professionals who constructed the structure that houses the Centre. Additionally, the GAF has been responsible for the aerial transport of large quantities COVID-19 equipment and logistics including PPEs, hand sanitizers and other emergency equipment to various 
parts of the country. All these have directly resulted in the prevention, treatment, and recovery of infected persons. In fact, the general fears citizens had about the presence of the security forces especially the army was enough to stop some people from frequenting the streets in violation of COVID-19 orders.

Furthermore, following the outbreak of the pandemic, the Ministry of Education collaborated with the Ghana Education Service to ensure the closure of schools at all levels. To ensure that school children were not adversely affected by the school closures, the Ministry of Education in collaboration with the Ministry of Communication and other relevant agencies rolled out distance learning programs for the students and pupil through innovative programs such as e-learning in the media. Candidates for of Basic Education Certificate Examinations and West Africa Secondary School Certificate Examinations (WASSCE) were also allowed to attend school to prepare for their impending examinations. Moreover, the Ministry worked with relevant agencies to disinfect all public schools in the country. At the tertiary level, institutions worked hard to develop online teaching and learning modes using various learning management systems. This adaptive creativity in the new unchartered era of coronavirus helped most tertiary institutions to complete the academic year without significant disruption to the school calendar. Institutions such as the University of Cape Coast and technical universities that could not finish their academic activities as scheduled were given extended periods to complete the academic. Currently, tertiary institutions continue to rely on online teaching and learning techniques in the face of the second wave of the pandemic. Ironically, this global threat has compelled Ghana to seek innovative solutions to teaching and learning that are consistent with learning in the twenty-first century and comparable to pedagogical models in the Western world.

The Ministry of Transport also played a pivotal role in the prevention and management of the COVID-19. For example, on April 17, 2020, the Ministry directed the Ghana Ports and Harbors Authority to suspend charges on all cargo. This was to ensure that shippers and other stakeholders did not take rational business decisions that could jeopardize the government's efforts at curbing the spread of the virus without causing irreparable damage to the economy. The Ministry further directed the Ghana Private Road Transport Union (GPRTU) to ensure a reduction in the number of passengers as part of the effort to realistically enforce social distance. Accordingly, commercial drivers reduced the number of passengers they picked. Unfortunately, the success of this policy during the lockdown was threatened as drivers became hesitant to enforce mask and social distancing compliance in the face of increasing social fatigue by passengers who gradually traveled without wearing nose masks. Again, currently many drivers and mates no longer wear the nose marks or use hand sanitizers whenever they exchange cash with passengers, a new development that is a far cry from the compliance regime just over a year ago.

Other ministries involved in this multi-sectoral intervention include the Ministry of Local Government, Ministry of Gender and Social Protection and Ministry of Water and Sanitation. The Ministry of Local Government, for instance, undertook several measures including relocating some market centers to places where proper social distance could be observed. It also led a massive nationwide fumigation and disinfection exercise in selected market centers across all 16 regions in the country. In the Greater Accra Region alone, some 137 major market centers were disinfected.

Again, in collaboration with the Ministries of Finance and Zongo and Inner-city Development, the Ministry of Gender and Social Protection embarked on the distribution of meals to the poor and vulnerable in the areas that were affected by the lockdown. In total, an amount of GHф54.3 million was disbursed for the meals project which involved the distribution of hot meals and dry food packages for poor households in the first three weeks of the partial lockdown. These items included bags of rice and local foods such as gari. Other items are tomato paste, cooking oil, sardines, crates of eggs, and bags of beans. According to Bamfo, Sarfo, Ansah and Amoah (2020), Ghana has witnessed dramatic increase in its fiscal spending due to the various measures taken to deal with the pandemic. To ensure equitable targeting and a non-partisan distribution of the food aid, the government channeled the intervention through faith-based organizations including the Christian Council of Ghana, the National Catholic Secretariat, the Ghana Pentecostal and Charismatic Council, the National Association of Charismatic and Christian Churches, the Charismatic Bishops Conference and the Office of the National Chief Imam, Ahmadiyya Muslim Mission and its allied humanitarian organizations.

Beyond the above stated ministries, stakeholders such as the media, religious bodies, corporate bodies, and individual citizens all played a crucial role in the management of the pandemic (Duti, 2021; Serwornoo and Abrokwah, 2020). The print and broadcast media contributed significantly in the communication activities in the prevention and management of COVID-19 infection. The media has been actively involved in creating awareness about the existence of the virus and educating the public on how to protect themselves and other persons from getting infected. At the peak of the pandemic, the Ghanaian media provided various platforms for critical expert stakeholders including virologists, doctors and other medical experts, and researchers in academia, among others, to discuss various issues relating to the COVID-19. Religious leaders and political actors were also engaged in the discussions to bring other perspectives to the issues. This helped to improve awareness and understanding of the coronavirus and the COVID-19 disease. Several media houses dedicated airtime to COVID- 
19 related issues in the collective effort to help manage the pandemic (Serwornoo and Abrokwah, 2020). For instance, media houses such as Joynews, Adom FM, Peace FM, Ghana Broadcasting Corporation and Citi FM dedicated public education programs solely for COVID-19 where doctors and health practitioners could come to talk and explain issues relating to the virus. Occasionally, media houses provided call-in-segments that gave viewers and listeners the opportunity to call and ask pertinent questions in line with the issues being discussed and other nagging questions they might have about the virus. Some media personalities who unfortunately got infected by the virus and recovered used the power of their platforms to share their experiences to further reinforce the real dangers that the disease poses to both public and individual health and the urgent need to observe all recommended safety protocols.

Moreover, leaders of the various religious bodies also used their platforms to create awareness about the virus (Duti, 2021). Initially, churches and mosques were quite empty in compliance with the restrictions. After a review of the ban on social gathering including gathering in churches and mosques, religious worship was permitted with strict adherence to COVID-19 protocols. Inside the church, social distancing was strictly observed, and the wearing of the nose mask became mandatory for every member attending church service. Some churches advised elderly members (those above 60 years) in their congregation and members with underlying health conditions to continue to stay home for their own safety. Handshakes and hugs were banned at all religious gatherings. In fact, initially most churches did not permit mass dancing during services. Some churches and mosques established health depots staffed with nurses and doctors to attend to members who showed signs of unwellness. Microphones were no longer shared amongst service leaders and singers and religious bodies ensured that frequently touched objects and surfaces were regularly cleaned and disinfected.

As part of the legal framework to fight the pandemic, the Parliament of Ghana passed the Novel Coronavirus (COVID-19) National Trust Fund Act, 2020 (Act 1013) in March, 2020. The Fund was set up to receive and manage contributions and donations from well-meaning individuals, groups, and corporate bodies to generate internal resources to support the fight against the pandemic. The Fund was to be managed by an independent board of trustees and chaired by the former Chief Justice of Ghana, Justice Sophia Akuffo. As a demonstration of leadership, President Akufo-Addo directed the Controller and Accountant General to pay his personal salary for the next three months (i.e., April, May, and June, 2020), into the Fund. Various individuals and corporate bodies donated several amounts of money, materials, and equipment to the Fund. The COVID-19 National Trust Fund, had, as of December 31, 2020, received a total amount of GHф57.1 million in cash donations, in addition to in-kind donations such as Personal Protective Equipment (PPE), laboratory supplies, vehicles, an ambulance and fuel coupons. Large quantities of perishable food items and mechanical and solar hand washing basins were also donated by individuals and corporate organizations. Out of this amount, the Fund, in accordance with its statutory mandate, disbursed GHф49.3million for different programs and procurement COVID-19 management and prevention.

At the individual level, Ghanaians generally cooperated with state agencies and other stakeholders in containing and managing the pandemic. Despite the initial skepticism that people had about the existence of the virus, most Ghanaians have come to the conclusion that the virus is real. Individuals tried to readjust their lifestyles and choices to adapt to the new normal. Many people embraced the safety protocols and other measures which were disseminated through the media to help contain the spread of the virus. One of the major breakthroughs in terms of containing the spread of COVID-19 has been the availability and procurement of the vaccine. Globally, Ghana became the first country outside India to receive COVID-19 vaccine doses through the COVAX Facility. This shipment was part of a first wave of arrivals that will continue into the future. Ghana received the COVAX shipment of 600000 doses of the AstraZeneca / Oxford vaccine, from the Serum Institute of India (SII) from Pune, India on February 23, 2021. Although there was an initial hesitancy by a section of the population to take the vaccine largely due to the myths and conspiracy theories surrounding the safety and efficacy of the vaccine, many people eventually accepted to take the vaccine as part of their commitment to help contain the spread of the virus in the country.

The various strategies and measures employed by key stakeholders to help Ghana deal with the pandemic have been characterized by a holistic, inter-sectoral and multi-stakeholder collective campaign. It is not surprising, therefore, that Ghana became the first African nation to lift its COVID-19 lockdown (Asiedu, cited in Antwi-Boasiako et al., 2021). Again, until recently, Ghana had the highest number of COVID-19 testing in the West African sub-region. Antwi-Boasiako et al. (2021) assert that although Ghana has been among the first ten countries in the African continent with the most infection cases, the ratio of infection to deaths shows that the country has been largely successful in managing its COVID-19 infections. Ghana's efforts have also been recognized in an article published in the Washington Post entitled "When it comes to coronavirus response, superpowers may need to study smaller nations". In this article, Ghana was found to be doing better in diverse ways than countries in Europe and North America. Indeed, it was added that the World Health Organization (WHO) at a point understudied Ghana's techniques and strategies underlining the country's success in the management of the COVID-19 (Antwi-Boasiako et al., 2021). In the Washington Post article, the authors, Adam 
Taylor and Miriam Berger praised Ghana's corps of community health workers, its innovative pool testing, and mentioned the fact that Ghanaians were "quite proactive in using their own budget to get a grip on the outbreak," as Osman Dar, the director of the Global Health Program of the London-based think tank Chatham House acknowledged (Taylor and Berger, 2020, par. 12). Similarly, according to Quakyi et al. (2021), Ghana's response was hailed as one of the best in Africa due largely to the innovative testing strategy regime and datadriven mechanism the country adopted.

On the local fronts, many Ghanaians via social media have praised the government's efforts to manage the COVID-19 (Antwi-Boasiako et al., 2021). Initiatives such as free water supply and free electricity by government were praised by the citizens (Smiley et al., 2020). Ghanaians described some of the interventions as good interventions which could ease the burden of access to clean water on poor households who often tend to compromise proper hygiene in crisis because of water insecurity (Smiley et al., 2020). Regardless of the gains made, Ghana's strategies and measures to manage the COVID-19 pandemic have not been without challenges. What is more is the fact that based on sudden increase in infection cases recently due to the advent of the Delta Variant, Ghana has revisited the initial measures and strategies she adopted to successfully deal with the pandemic.

\section{Challenges associated with the management of COVID-19 situation in Ghana}

As already shown, Ghana initially paid much more attention to the management of her COVID-19 situation. Indeed, the seriousness of the country's initial response to the pandemic was echoed by the president in March 2020 as follows, "We know how to bring the economy back to life. What we did not know is how to bring people back to life." The statement from the president resonated very well with the entire nation's zeal and enthusiasm which characterized the fight against the pandemic. This led to commendable achievement during the initial stages of the pandemic. However, a little over a year ago when these statements were made by the president, Ghana seems to be battling with gaps manifesting in rhetoric and reality. There are concerns with respect to how the country has been responding to the pandemic especially since the late 2020 .

Though at a relatively slow rate, Ghana continues to witness an increase in the number of infections, with Accra, the capital city, having close to $88 \%$ of all cases (Quakyi et al., 2021). Additionally, the seriousness which characterized contact tracing and testing initially has scaled down dramatically in most part of the country. This was necessitated by Ghana Health Service's decision to focus tracing and testing on symptomatic cases to the neglect of community surveillance (Aku, 2020). As of July 14, 2021, Ghana had recorded 97,728 cases with 94,612 who had recovered and 802 deaths (Worldometer, 2021). From only two cases reported in March 2020 to about 100, 000 just over a year ago, the country continues to witness a steady increase in the number of COVID19 cases which should be a major concern to all stakeholders including government, employers, the media and the citizenry.

Admittedly, Ghana seems to re-visit some of the testing strategies adopted over a year ago to deal with the spread of the virus. However, this attempt has been criticized by a number of scholars. For instance, in the views of Quakyi et al. (2021), the rebound in COVID-19 testing in Ghana since January 2021 is mainly due to increased care to seek for COVID-19-like symptoms at health facilities, and high demand for testing at private laboratories by some individuals and employers. The situation is further driven partly by travel requirements and reactivation of contact tracing in some cities of the country.

Besides, as a way protecting health personnel who were directly involved in the fight against the disease, the country procured several PPEs and hand sanitizers following the announcement by the president. However, despite the announcement, health personnel and health facilities continued to experience inadequate supply of PPE and hand sanitizers. The situation has not really changed in most health facilities even now. In fact, unlike the initial stages of the fight where corporate bodies helped in the supply of PPE and sanitizers to health facilities, since the late 2020 these donations appeared to have ceased even in the face of increased number of cases (Quakyi et al., 2021).

Again, though the number of public testing facilities providing free testing has increased from two to nine (Ghana Health Service, 2021), there are delays in testing results. This seems to be a common phenomenon in the fight against the virus especially in recent times. The situation is attributed to high testing load, and frequent shortages of testing reagents. Needless to state that delays in getting test results constitutes a major threat to community and workplace transmission, especially in times like this when many employers are asking employees to resume work (Quakyi et al., 2021).

Moreover, health personnel protection and compensation issues create a challenge in Ghana's fight against the disease coupled with shortage of beds especially for intensive care. In their recent study of 25 health facilities in Ghana, Siaw-Frimpong et al. (2021) found that only $43 \%$ of the 23 public facilities had intensive care units (ICUs) providing 14 functional ICUs in addition to 2 private facilities.

Furthermore, protective measures instituted in schools appear have not been without challenges (Quakyi et al., 2021). It is reported that despite the efforts put in place in schools to manage the spread of the virus, 
currently there are no clear procedures to ensure compliance (Ansah, 2021). It is, therefore, no wonder that some schools continue to report confirmed cases of infection in recent times. Quakyi et al. (2021) call for routine surveillance of students irrespective of symptomatology in so long as schools remain open in the country coupled with rapid case-cluster investigations. This, the authors believe, is a vital way to increase protection of students.

Similarly, the situation in some workplaces is not different from what is happening in some schools. Low risk perception and fear of stigmatization seem to contribute to increased refusal of employees to disclose COVID-19 status to employers (Quakyi et al., 2021). Clearly, this complicates efforts to properly handle the situation by most employers, leading to possible increase in infections. The situation at the workplace appears to be worsened by the recent altercation in Ghana's parliament, where an effort to screen members of parliament (MPs) and their employees was met with resistance. Indeed, there were as many 60 MPs who refused testing and even those who tested positive refused isolation and continued attending parliamentary proceedings (Kokutse, 2021). The apparent poor handling of the disease in Ghana's highest law-making body seems to be symptomatic of what was witnessed in other workplaces. Quakyi et al. (2021) appear to lampoon the poor management of workplace outbreak of the COVID-19 recently and call for a more comprehensive strategy to dealing with the situation at workplace instead of the country relying on discretionary measures.

Moreover, even though Ghanaian media played significant roles in the fight against the pandemic initially, their efforts especially in recent times present a challenge to the comprehensive management of the situation. The media generally has not provided science-driven coverage of the COVID-19 situation of Ghana. Suffice to state that measures and data by stakeholders including government and its agencies have been reported without any critical analysis. Critical questions were not raised as very few independent health professionals and academics were given platforms to discuss the measures and issues related to COVID-19 in Ghana (Quakyi et al., 2021). Again, the momentum which characterized media coverage and reportage seems to have scaled down immensely especially after the huge gains the country made in the first half of the year 2020 . This is heightened by inadequate risk communication strategies which contributes to misinformation and low compliance with safety measures (Quakyi et al., 2021). The authors believe that only comprehensive science-driven response and detailed age-disaggregated reports on new cases from both public and private health sectors and from communities can help maximize the success with respect to the management of the pandemic.

Finally, observance of the safety protocols in religious settings has been very poor in the country in recent times, with many of these religious groups clearly disregarding most of the safety protocols. Unlike what happened during the initial stages of pandemic where religious bodies actively participated in the fight against the disease, there seems to be a general discontent regarding the safety protocols among the religious settings which seem to be fueled by the arrival of the vaccine. Of late, religious bodies generally disregard the preventive measures instituted to tame the COVID-19 pandemic including the safety protocols despite the rising number of infection cases. Indeed, the general apathy across the religious arena seems to be further strengthened by religious fundamentalists who continue to raise false hope in preventive measures which are not informed by any scientific analysis (Barua et al., 2020).

\section{Conclusion}

Like many other countries, Ghana saw the pandemic as affecting every fibre of society. No sector of the economy was to be exempted from the ravaging consequences posed by the virus. This recognition informed the approach adopted in dealing with the pandemic. Both top-down and bottom-up approaches were employed to deal with the pandemic. Indeed, the nature and severity of COVID-19 demanded a multifaceted approach involving various stakeholders to curb its spread. This position was clearly acknowledged by various stakeholders of Ghana. For example, the Government set up an Inter-Ministerial Committee on Coronavirus Response chaired by President Nana Addo Dankwa Akufo-Addo himself to deal with the situation. Again, specific ministries were assigned clear roles they needed to play as part of ensuring success in the management of the pandemic. Generally, at the initial stages, each ministry played its role effectively to help contain and manage the spread of the pandemic. Corporate bodies, religious groups and the media all understood the enormity of the task ahead and so positioned themselves to help deal with the pandemic. Besides, individual citizens also cooperated with other stakeholders to maximize the success of the measures put in place to manage the spread of the virus. The all-inclusive approach to the fight against the virus led to the remarkable success chalked in the management of the pandemic in Ghana especially in the first half of the year 2020. The success chalked was recognized even beyond the shores of the country.

Despite the success chalked, there are serious challenges in areas such as logistics, personnel, funds, and health infrastructure which need to be addressed to strengthen the country's capacity to deal with the pandemic. Also, there seems to be general apathy evident even among state authorities in recent times in dealing with the pandemic. Given the seeming unpredictable nature of the virus, caution cannot be thrown on to the wind with respect to the level of commitment required to curtail the further spread of the virus. The initial enthusiasm and 
zeal which characterised the several efforts by the various stakeholders to contain and manage the spread of the virus should be rekindled to avoid any unforeseen consequences especially in the face of the new wave which is christened "Delta variants". All stakeholders are encouraged to relight their commitment and enthusiasm which they demonstrated especially during the first wave of the pandemic.

Though the initial management approach adopted by Ghana was worthy of emulation especially in the subregion, recent case counts suggest that the country needs to demonstrate more commitment toward the fight against the pandemic to avoid any unforeseen happenings in respect of the spread of the virus. A crucial element which Ghana should consider as part of the overall strategies to offset any further social, economic, political and psychological losses especially in the face of the third wave of the virus is effective communication. Effective communication requires that stakeholders pay much attention to the sources of information and channels of transmission of the information associated with the pandemic, a position whose relevance finds expression in the theory of social risk amplification and attenuation.

\section{References}

Aduhene, D. T. and Osei-Assibey, A. (2021). Socio-economic impact of COVID-19 on Ghana's economy: Challenges and prospects. International Journal of Social Economics, 48(4), 543-556.

Afriyie, D. K., Asare, G. A., Amponsah, S. K. and Godman, B. (2020). COVID-19 pandemic in resource-poor countries: challenges, experiences and opportunities in Ghana. The Journal of Infection in Developing Countries, 14(08), 838-843.

Agyeman-Manu, K. (2020). Covid-19 response; Ghana's Experience Retrieved from https://apps.who.int/gb/COVID-19/pdf_files/07_05/Ghana.pdf

Aku, J. (2020). COVID-19: Symptomatic persons to be prioritized testing as GHS clears backlog of 23, 000 samples. Graphic Online, 2020. Retrieved from: https://www.graphic.com.gh/news/general-news/covid-19symptomatic-persons-to-be-prioritised-for-testing-as-ghs-clears-backlog-of-23-000-samples.htm/ [Accessed 13 July 2021]

Ansah, M. (2021). Akosombo international school adopts shift system to stop spread of COVID-19. Citi Newsroom, 2021. Retrieved from: https://citinewsroom.com/2021/02/akosombo-international-schooladopts-shift-system-to-stop-spread-of-covid-19. [Accessed 13 July 2021]

Antwi-Boasiako, J., Abbey, C. O., Ogbey, P. and Ofori R. A. (2021). Social distancing strategies to tackle the pandemic. Revista de Administraçäo Pública 55 (1). https://doi.org/10.1590/0034-761220200507

Asante, L. and Mills, R. (2020). Exploring the Socio-Economic Impact of COVID-19 Pandemic in Market places in Urban Ghana, Sage Publications

Bamfo, I., Sarfo, J.O., Ansah, E.W. and Amoah, S.K. (2020). The Impact of Health on Economic Development: Ghana's COVID-19 Management So Far. European Journal of Economic Studies, 9(1), pp.3-10.

Barua, Z., Barua, S., Aktar, S., Kabir, N. and Li, M. (2020). Effects of misinformation on COVID-19 individual responses and recommendations for resilience of disastrous consequences of misinformation. Progress in Disaster Science 8. https://doi.org/ 10.1016/j.pdisas.2020.100119

Brown, N. (2020). Dealing with the virus of indiscipline amidst COVID-19. citinewsroom.com

Duti, V. (2020). Silver linings of the COVID-19 crisis in Ghana. Perspectives of WASH systems advocate and watcher. IRC Ghana.

Galal, S. (2021). Number of coronavirus (COVID-19) cases in the African continent as of June 24, 2021, by country. Available at: https:/www.statista.com/statistics/1170463/coronavirus-cases-in-africa/

Ghana Health Service. (2020). Situation update, Covid-19 outbreak in Ghana as at 7 May 2020 Accra, Ghana: Author. Retrieved from: https:/ghanahealthservice.org/covid19/archive.php » https://ghanahealthservice.org/covid19/archive.php

Ghana Health Service. (2021). Ghana's Outbreak Response Management Update" Retrieved from: https://ghanahealthservice.org/covid19/latest.php

Ghana News Agency. (2020, May 08). Ghana records 921 new COVID-19 cases. Retrieved from: https://www.gna.org.gh/1.18262013

Hale, T; Petherick, A; Phillips, T. and Webster, S. (2020). Variation in government responses to COVID19(Working Paper, 31). Oxford, UK: Blavatnik School of Government, University of Oxford. Retrieved from http://www.bsg.ox.ac.uk/covidtracker

Henaku, E. A. (2020). COVID-19 online learning experience of college students: The case of Ghana. International Journal of Multidisciplinary Sciences and Advanced Technology, 1(2), 54-62.

Kano, L., Tsang, E. W. and Yeung, H. W. C. (2020). Global value chains: A review of the multi-disciplinary literature. Journal of International Business Studies. https://doi.org/10.1057/s41267-020-00304-2.

Kasperson, R. E. and Kasperson, J. X. (1996). The social amplification and attenuation of risk. The Annals of the American Academy of Political and Social Science, 545: 95-105.

Kaye, A. D., Okeagu, C.N., Pham, A.D., et al. (2020). Economic impact of COVID-19 pandemic on healthcare 
facilities and systems: International perspectives. Retrieved from: https://www.ncbi.nlm.nih.gov/pmc/articles/PMC7670225/

Kim, D. (2020). Why automakers are affected most from cascade of factory closures in China: China-made wiring harnesses have been kept in small stocks for efficiency, The Korean Herald. Retrieved from https://www.koreaherald.com/view.php?ud=20200205000735. Accessed 24 Apr 2020.

Kokutse, F. (2021). Ghana suspends Parliament amid a surge in COVID-19 cases associated with press, 2021. Retrieved from: https://apnews.com/article/ghana-health-coronavirus-pandemic-africa-west$34 \mathrm{f} 5 \mathrm{f} 94 \mathrm{ce} 8379 \mathrm{c}=\mathrm{acbcec} 302 \mathrm{a} 414477 \mathrm{dee}$

KPMG. (2020). Ghana - COVID-19-Related travel restrictions and safety. Retrieved from: https:/home.kpmg/xx/en/home/insights/2020/03/flash-alert-2020-094.html

Lim, G. and Lee, C. (2020). Catching-up and the way forward in the electronics industry: The case of China (pp. 1-14). NCPA Case Study-2020-01

McKibbin, W. and Fernando, R. (2020). The economic impact of COVID-19. Economics in the Time of COVID-19, 45. Relations between health and development Retrieved from: https://pubmed.ncbi.nlm.nih.gov/8466652/\#: :text=Throughout\%20history\%2C\%20improved\%20health\% 20has,compared $\% 20$ to $\% 20$ simple $\% 20$ economic $\% 20$ growth

Nsibambi, A. (2001). Panel hears range of views on globalization and the state. United Nations. Meetings Coverage and Press Releases.

President of Ghana. (2020a). President Akufo-Addo Addresses Nation on Updates to Ghana's Enhanced Response to the Coronavirus Pandemic Retrieved from: http://presidency.gov.gh/index.php/briefingroom/speeches/1546-president-akufo-addo-addresses-nation-on-updates-to-ghana-s-enhanced-response-tothe-coronavirus-pandemic

President of Ghana. (2020b). President Akufo-Addo Address to the Nation by on Updates to Ghana's Enhanced Response to the Coronavirus Pandemic Retrieved from: http:/www.presidency.gov.gh/index.php/briefingroom/speeches/1555-address-to-the-nation-by-president-akufo-addo-on-updates-to-ghana-s-enhancedresponse-to-the-coronavirus-pandemic

Quakyi, N. K. (2020). COVID-19 spread during campaign events. VOA

Quakyi N.K., Asante, N.A.A., Nartey, Y.A., Bediako, Y. and Sam-Agudu, N.A. (2021). Ghana's COVID-19 response: the Black Star can do better. BMJ Global Health, 6, 1-5. doi:10.1136/bmjgh-2021-005569

Ruger, J.R. (2003). Health and Development. Retrieved from: https://www.ncbi.nlm.nih.gov/pmc/articles/PMC4006200/

Serwornoo, M. and Abrokwah, R. (2020) "Ghana Coronavirus and the Media" Retrieved from https://en.ejo.ch/ethics-quality/ghana-coronavirus-and-the-media

Siaw-Frimpong, M., Touray, S. and Sefa, N. (2021). Capacity of intensive care units in Ghana. J Critical Care, 61, 76-81.

Smiley, S. L; Agbemor, B. D; Adams, E. A. and Tutu, R. (2020). COVID-19 and water access in Sub-Saharan Africa: Ghana's free water directive may not benefit water insecure households. African Geographical Review, 39(4), 324-344. Retrieved from https://doi.org/10.1080/19376812.2020.1810083

Tabong, P. T. N. and Segtub, M. (2021). Misconceptions, misinformation and politics of COVID-19 on social media: A multi-level analysis in Ghana. Frontiers in Communication, 6 (May): 1-13. doi: 10.3389/fcomm.2021.613794

Taylor, A. and Berger, M. (2020, 16 May). "When it comes to coronavirus response, superpowers may need to study smaller nations," Washington Post.

The World Bank. (2020). Global Economic Prospects. Retrieved from: https://www.worldbank.org/en/publication/global-economic-prospects

The World Bank (2020). The Global Economic Outlook During the COVID-19 Pandemic: A Changed World. Retrieved from: https://www.worldbank.org/en/news/feature/2020/06/08/the-global-economic-outlookduring-the-covid-19-pandemic-a-changed-world

Xinhuanet. (2021). Ghana extends incentive package for COVID-19 frontline health workers. Retrieved from: http://www.xinhuanet.com/english/2020-06/29/c_139174283.htm Wang, C.,

Wang, Z., Wang, G., Yiu-Nam Lau, J., Zhang, K. and Li, W. (2021). COVID-19 in early 2021: Current status and looking forward. Signal Transduction and Targeted Therapy, 6: 1-14. https://doi.org/10.1038/s41392021-00527-1

Worldometer. (2021). Coronavirus Cases. Retrieved from: https://www.worldometers.info/coronavirus/

World Health Organization. (2021). WHO Health Emergency Dashboard: Ghana. Retrieved from: https://covid19.who.int/region/afro/country/gh

Zhou, Y. (2021). COVID-19 and its challenges for the global economy. Retrieved from: https://acde.crawford.anu.edu.au/news-events/news/17196/covid-19-and-its-challenges-global-economy 